\title{
Evidence for oligoclonal B cell expansion in the peripheral blood of patients with rheumatoid arthritis
}

\author{
DAVID A FOX AND BRIAN R SMITH
}

From the Department of Rheumatology and Immunology, and Department of Medicine, Brigham and Women's Hospital, Harvard Medical School, Boston, MA; and the Division of Rheumatology, Department of Internal Medicine, University of Michigan Medical Center, Ann Arbor, MI, USA

SUMmaRY Peripheral blood lymphocytes from patients with rheumatoid arthritis and osteoarthritis were examined for evidence of oligoclonal B cell expansion using the computer assisted flow cytometric technique of kappa-lambda $(x-\lambda)$ analysis. Eleven of 29 patients with rheumatoid arthritis but only one of 16 with osteoarthritis gave abnormal results $(p<0.025)$. Abnormal $x-\lambda$ determinations did not correlate with age, duration of disease, presence of rheumatoid factor, or other clinical and laboratory parameters. Therapy with oral or intramuscular gold compounds appeared to diminish the incidence of $x-\lambda$ abnormality. These findings may indicate defective control of clonal B cell proliferation in rheumatoid arthritis.

Key words: lymphocytes, flow cytometry, gold compounds.

Rheumatoid arthritis (RA) is characterised by serological abnormalities, notably the presence of rheumatoid factor (RF), ${ }^{1}$ which indicate pathological B cell responses. Relatively scant information, however, is available concerning the phenotypic characterisation of B lymphocytes in patients with RA or the possible presence of abnormal numbers of $B$ cells belonging to particular subsets or individual clones.

Recently, computer assisted flow cytometric methods have been developed that permit detection of subtle monoclonal or oligoclonal expansion of $B$ cell clones in the peripheral blood lymphocyte population of patients with lymphoproliferative disorders, even when the lymphocyte populations are normal by conventional morphological criteria. $^{2-6}$ Using such a technique, called ' $x-\lambda$ analysis', we asked whether evidence of oligoclonal B cell excess could be detected in RA.

\section{Patients and methods}

PATIENTS

We studied 29 outpatients with definite or classical RA (mean age 53, range 35-65). Twenty four

Accepted for publication 5 June 1986.

Correspondence to Dr David A Fox, University of Michigan Medical Center, Department of Internal Medicine, Division of Rheumatology, Room 3918 Taubman Center, Ann Arbor, Michigan 48109, USA. were enrolled in a multicentre, double blind, placebo controlled trial of (1-thio- $\beta$-D-glucopyranosato) (triethylphosphine) gold 2,3,4,6-tetra-acetate, (auranofin) (unpublished data). Of these 24, 12 patients were assigned to receive auranofin and 12 placebo. Five patients were recruited from the general clinic population at the time of initiation of intramuscular aurothioglucose (Solganal) injections. All 29 of the patients were taking salicylates or nonsteroidal anti-inflammatory drugs, with or without low doses of corticosteroids ( $\leqslant 10 \mathrm{mg}$ prednisone daily).

The control group consisted of 16 patients with clinically and radiographically characteristic osteoarthritis (OA) of the hands, hips, and/or knees (mean age 65, range 47-85). No patient in either group carried a diagnosis of lymphoma, leukaemia, or other neoplastic disease. The RA group contained 20 women and nine men, and the OA group contained 10 women and six men.

K A P P A - L A M B D A ANALYS IS

Peripheral blood mononuclear cells were isolated by centrifugation over a Ficoll-Hypaque gradient, and aliquots of $10^{6}$ cells were stained with saturating amounts of a $F\left(a b^{\prime}\right)_{2}$ fragment of rabbit antibody highly specific for either human $x$ or $\lambda$ light chains, followed by saturating amounts of fluoresceinated goat antibody to rabbit IgG. $^{2-6}$ Samples were analysed on a Becton-Dickinson FACS II, with 


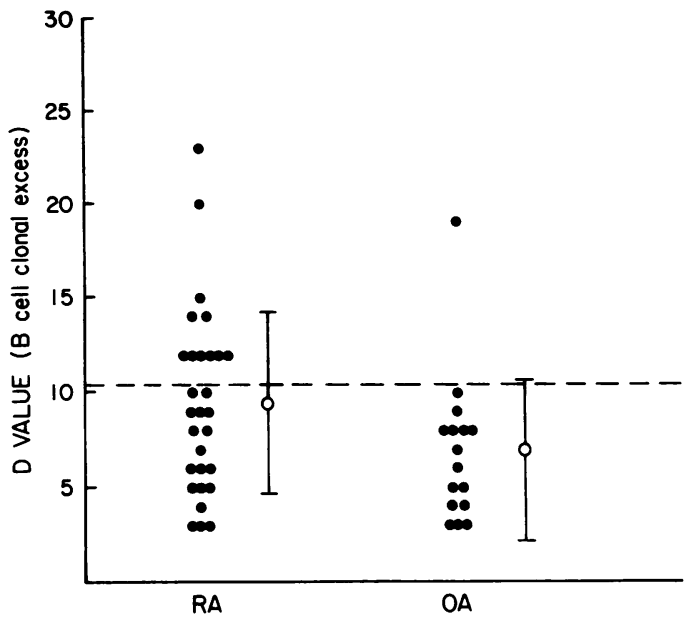

Fig. 1 Oligoclonal $B$ cell excess ( $D$ value) in patients with $R A$ and $O A$. Mean $(S D)$ for $O A=6.9(3 \cdot 8)$, for $R A=9.4$ (4.9).

scatter gates set to exclude monocytic cells, and histograms of fluorescence intensity versus cell number were obtained. ${ }^{24-6}$

Normal B cells express either the $x$ or the $\lambda$ light chain, but not both, and the fluorescence distribution profile for each light chain represents the sum of fluorescence intensities of all B cell clones present in the normal heterogeneous B cell population. Even if unequal total numbers of $x$ and $\lambda$ positive cells are present the relative shapes and positions of the fluorescence intensity histograms are nearly identical since the normal frequency distributions of intensity of $x$ and $\lambda$ surface expression are very similar in a mixed population containing many $B$ cell clones. ${ }^{24-6}$ In patients with $B$ cell lymphoproliferative syndromes the presence of an expanded monoclonal or oligoclonal population results in a distortion or shift of either the $x$ or $\lambda$ fluorescence histogram, which is easily visible upon superimposition of the two curves. ${ }^{2-6}$ In the present study this difference was measured by computer analysis, as previously described, to yield the Kolmogorov-Smirnov statistic (D value). ${ }^{4}$ The $\mathrm{D}$ value for samples obtained from normal, healthy control subjects is $\leqslant 10$ and for 20 healthy controls analysed concurrently with the present study the D value was $5 \cdot 8(3.5)$ (mean (SD), range 2-9). For most patients with RA $x-\lambda$ analysis was performed serially over a three to six month period after initiation of either aurothioglucose, or blinded auranofin, or placebo therapy. For patients with $\mathrm{OA}$ a single analysis was performed.

\section{Results}

In order to detect small numbers of monoclonal or oligoclonal B lymphocytes in RA and OA peripheral blood $x-\lambda$ analysis was performed and the $D$ value calculated as described in 'Patients and methods'. As shown in Fig. 1, 11 of 29 patients with RA but only one of 16 patients with OA yielded abnormal values $\left(\chi^{2}=5 \cdot 3,0 \cdot 01<p<0 \cdot 25\right)$. In most of $\vec{\bullet}$ the patients with RA it was possible to obtain seria samples for follow up $x-\lambda$ analyses at one, thre and/or six months after the original determination As shown in Fig. 2, three of 11 patients followed up while receiving placebo had abnormal $D$ values at the last follow up compared with four of 12 when first studied (no follow up studies were obtained in one patient). Of the four patients with initially abnormal $D$ values, three subsequently normalised, and two patients with initially normal $D$ values became abnormal by six months. These results indicate that in a given patient with RA evidence of
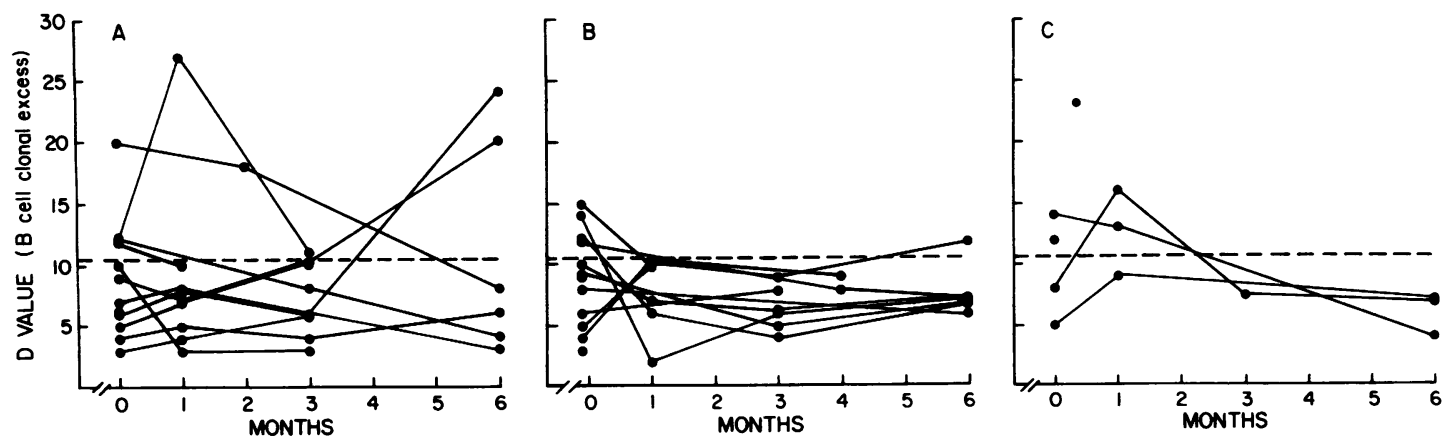

Fig. 2 Oligoclonal $B$ cell excess ( $D$ value) in patients with $R A$ followed up while receiving $(A)$ placebo, $(B)$ auranofin, or (C) aurothioglucose. 
Table 1 Comparison of patients with $R A$ with and without $B$ cell clonal excess

\begin{tabular}{lcc}
\hline & $\begin{array}{l}\text { With } B \text { cell } \\
\text { clonal excess }\end{array}$ & $\begin{array}{l}\text { Without } B \text { cell } \\
\text { clonal excess }\end{array}$ \\
\hline Age & $53 \cdot 7$ & $52 \cdot 4$ \\
Duration of RA & $10 \cdot 4$ & $9 \cdot 8$ \\
Prednisone dose (mg/day) & $1 \cdot 6$ & $2 \cdot 6$ \\
Functional class & $2 \cdot 6$ & $2 \cdot 4$ \\
Anatomical class & $2 \cdot 9$ & $2 \cdot 9$ \\
Rheumatoid factor positive & $9 / 11$ & $12 / 18$ \\
\hline
\end{tabular}

oligoclonal B cell excess may be transient, even if the patient is not treated with a disease modifying drug.

The data in Fig. 2 also show that of 13 patients with RA followed up during oral or intramuscular gold treatment, only one had an abnormal $\mathrm{D}$ value at last follow up compared with seven of 17 at the start of gold therapy $\left(\chi^{2}=4 \cdot 22, p<0 \cdot 05\right)$. All patients who were initially abnormal and were studied serially while receiving gold developed normal D values, while two initially normal patients became abnormal, one transiently. Serial samples could not be obtained from four patients, two of whom had abnormal $\mathrm{D}$ values on the single occasion that they were studied.

To look for clinical or laboratory characteristics that might correlate with an abnormal $x-\lambda$ analysis patients were grouped according to whether their initial D value was normal or abnormal and compared with respect to several parameters. As shown in Table 1 the groups were comparable with respect to age, duration of RA, prednisone dose, functional or anatomical class, and presence of RF. Moreover, no significant differences were observed in any of the following parameters: sex, duration of morning stiffness, time to fatigue, pain (measured on an analogue scale), overall health (estimated independently by patient and physician on an analogue scale), number of swollen joints, number of tender or painful joints, grip strength, 50 foot walking time, packed cell volume, platelet count, Westergren erythrocyte sedimentation rate, RF titre, total number of $\mathrm{B}$ cells, and the relative proportion of $\mathrm{T} 4+$ and $\mathrm{T} 8+$ lymphocytes. Thus the presence of oligoclonal B cell excess in patients with RA did not identify any readily discernible clinical subset.

\section{Discussion}

In the present study we used the technique of $x-\lambda$ analysis to demonstrate oligoclonal B cell excess in the peripheral blood of an appreciable proportion of patients with RA. Similar findings were rarely seen in a control group of patients with OA. Although the RA group included some patients younger than any in the OA group, this difference does not account for the observed findings since $(a)$ no similar abnormalities were observed in an additional control group of 20 healthy subjects aged 20-50 and (b) within the RA group there was no correlation between age and a normal or abnormal $x-\lambda$ analysis.

Several studies have indicated that RA is characterised by polyclonal activation of peripheral blood B cells, detectable either by plaque forming cell assays ${ }^{78}$ or by alterations in the ratio of surface IgM to IgD and in the ability of B cells to rosette with mouse erythrocytes. ${ }^{9}$ One possible explanation for such findings is the impaired ability of RA T cells to regulate $B$ lymphocyte activation induced by the ubiquitous Epstein-Barr virus, ${ }^{10-13}$ a defect that may be related to abnormal sensitivity of RA T cells to monocyte derived prostaglandin E. ${ }^{14}$ Complex abnormalities have also been observed in the regulation by RA T cells of immunoglobulin production driven by pokeweed mitogen. ${ }^{15-17}$ Moreover, $\mathrm{RF}$ itself may function as an additional polyclonal $\mathrm{B}$ cell activator. ${ }^{18}$

Examination of RA B cell function in the synovial compartment has shown results not always apparent from studies using peripheral blood lymphocytes. Thus a subset of patients with active, generalised synovitis had increased numbers of B cells spontaneously secreting immunoglobulin that were detectable in synovial fluid but not peripheral blood. ${ }^{19}$ The synovial membrane may be a significant site of production of $\mathrm{RF}{ }^{20}$ which together with anticollagen antibodies and other immunoglobulins may be trapped in immune complexes within articular cartilage. $^{21}$ Of particular interest is the fact that recent studies have demonstrated that a majority of RA synovia in culture secrete IgG showing oligoclonal banding. ${ }^{22}$ The above information suggests that the abnormalities detected in the present study could potentially be more striking with the synovial lymphocyte population. Oligoclonal IgG was also found, however, in the serum of $17 \%$ of hospitalised RA patients compared with $3 \%$ of hospitalised controls. $^{22}$ The oligoclonal bands were thought not to represent IgG RF primarily, and there is as yet no information regarding the antigen(s) reactive with these immunoglobulins. Although RF production represents activation of a restricted set of $B$ cell clones, ${ }^{23-25}$ it is probable that the findings in the present study also do not relate solely to B cells producing RF, given the lack of correlation between an abnormal $x-\lambda$ pattern and the presence or titre of RF. Nevertheless, this issue will require further investigation. 
Our data also suggest that in some patients with RA gold therapy may be accompanied by suppression of detectable oligoclonal B cell expansion in peripheral blood. Additional longitudinal studies of patients receiving a variety of disease modifying agents would be of interest, given the ability of both gold and penicillamine to suppress in vitro synthesis of IgG and IgM RF by RA B cells, ${ }^{26}$ and in vivo RF titres. ${ }^{27} 28$

In the present study patients were not systematically characterised with respect to the presence or absence of Sjögren's syndrome. Sjögren's syndrome is characterised by polyclonal hypergammaglobulinaemia and can evolve into a monoclonal B cell neoplasm. ${ }^{29-32}$ Recent studies using high resolution electrophoretic techniques have identified monoclonal light chains in the serum and urine of a high proportion of patients with Sjögren's syndrome. ${ }^{33} 34$ $x-\lambda$ Analysis of B cells from patients with Sjögren's syndrome, both primary and secondary, and patients with other rheumatic diseases, such as systemic lupus erythematosus, will be of interest.

Several studies have suggested that patients with RA are subject to an increased risk of $B$ cell neoplasms not related to exposure to immunosuppressive drugs. ${ }^{35-40}$. The multiple immunoregulatory disturbances found in RA provide a possible explanation for this phenomenon. ${ }^{41}$ Although the abnormalities in $x-\lambda$ analysis found among our RA patients are more subtle than those seen in overt lymphoma, they are comparable to findings in patients with lymphoma in apparent remission who subsequently developed a clinical recurrence. ${ }^{2}{ }^{4}$ In patients with RA such abnormalities may indicate defective $T$ cell control of clonal $B$ cell expansion which, in a small number of individuals, could eventually result in overt B cell malignancy. At present, however, this hypothesis remains speculative, and larger longitudinal studies will be needed to address such issues definitively.

We are grateful to the clinical staff of the Rheumatology Ambulatory Center, Brigham and Women's Hospital, for referral of patients. We thank Mary Scammon and Holly Taylor for assistance with collection of clinical data, and are grateful to Rennie Hughes and Ardith Listeman for secretarial assistance.

\section{References}

1 Kunkel H G, Muller-Eberhard H J, Fudenberg H H, Tomasi T B. Gamma globulin complexes in rheumatoid arthritis and certain other conditions. J Clin Invest 1961; 40: 117-29.

2 Ault K A. Detection of small numbers of monoclonal B lymphocytes in the blood of patients with lymphoma. $N$ Engl J Med 1979; 300: 1401-5.

3 Ligler F S, Smith R G, Kettman J R, et al. Detection of tumor cells in the peripheral blood of nonleukemic patients with $B$ cell lymphoma: analysis of 'clonal excess'. Blood 1980; 55: 792-801.
4 Smith B R, Robert N J, Ault K A. In Waldenstrom's macroglobulinemia the quantity of detectable circulating monoclonal B lymphocytes correlates with clinical course. Blood 1983; 61: 911-4.

5 Smith B R, Weinberg D S, Robert N J, et al. Circulating monoclonal B lymphocytes in non-Hodgkin's lymphoma. N Engl J Med 1984; 311: 1476-81.

6 Weinberg D S, Pinkus G S, Ault K A. Cytofluorimetric detection of $\mathrm{B}$ cell clonal excess: a new approach to the diagnosis of B cell lymphoma. Blood 1984; 63: 1080-7.

7 Al-Balaghi S, Strom H, Moller E. High incidence of spontaneous Ig-producing lymphocytes in peripheral blood and synovial fluid of patients with active seropositive rheumatoid arthritis. Scand J Immunol 1982: 16: 69-76.

8 Pardo I, Levinson A I. Circulating immunoglobulin-secreting cells in rheumatoid arthritis. Clin Immunol Immunopathol 1983; 29: 29-34.

9 Youinou P Y, Irving W L, Shipley M, Hayes J, Lydyard P M. Evidence for $B$ cell activation in patients with active rheumatoid arthritis. Clin Exp Immunol 1984; 55: 91-8.

10 Bardwick P A, Bluestein H G, Zvaifler N J, Depper J M, Seegmiller $J$ E. Altered regulation of Epstein-Barr virusinduced lymphoblast proliferation in rheumatoid arthritis lymphoid cells. Arthritis Rheum 1980; 23: 626-32.

11 Tosato G, Steinberg A D, Blaese R M. Defective EBV-specific suppressor T-cell function in rheumatoid arthritis. $N$ Engl J Med 1981; 305: 1238-43.

12 Depper J M, Bluestein H G, Zvaifler N J. Impaired regulation of Epstein-Barr virus-induced lymphocyte proliferation in rheumatoid arthritis is due to a T cell defect. J Immunol 1981; 127: $1899-902$.

13 Depper J M, Zvaifler N J. Epstein-Barr virus: its relationship tø the pathogenesis of rheumatoid arthritis. Arthritis Rheum 1981 24: 755-61.

14 Hasler F, Bluestein H G, Zvaifler N J, Epstein L B. Analysis of the defects responsible for the impaired regulation of EBV: induced B cell proliferation by rheumatoid arthritis lymphocytes: II. Role of monocytes and the increased sensitivity of rheumatoid arthritis lymphocytes to prostaglandin E. J Immunol 1983; 131: 768-72.

15 Bellamy N, Cairns E, Bell D A. Immunoregulation in rheumatoid arthritis: evaluation of T lymphocyte function in the control of polyclonal immunoglobulin synthesis in vitro. $J$ Rheumatol 1983; 10: 19-27.

16 Romain P L, Burmester G R, Enlow R W, Winchester R J. Multiple abnormalities in immunoregulatory function of synovial compartment $T$ cells in patients with rheumatoid arthritis: recognition of a helper augmentation effect. Rheumatol Int 1982; 2: $121-7$

17 Egeland T, Lea T, Mellbye O J. T-cell immunoregulatory functions in rheumatoid arthritis patients. Scand J Immunol 1983; 18: $355-62$.

18 Hobbs M V, Morgan E L, Baker N L, Weigle W O. Regulation of antibody responses by rheumatoid factor: I. Polyclonal activation of human B cells by rheumatoid factor-containing preparations from seropositive plasma. J Immunol 1985; 134: 223-9.

19 Bell D A, Pinto J. Distribution of activated B lymphocytes in the circulation and synovial fluid in rheumatoid arthritis. Clin Immunol Immunopathol 1984; 31; 272-81.

20 Cecere F, Lessard J, McDuffy S, Pope R M. Evidence for the local production and utilization of immune reactants in rheumatoid arthritis. Arthritis Rheum 1982; 25: 1307-15.

21 Jasin H E. Autoantibody specificities of immune complexes sequestered in articular cartilage of patients with rheumatoid arthritis and osteoarthritis. Arthritis Rheum 1985; 28: 241-8.

22 Hoffman W L, Douglass R R, Smiley J D. Synthesis of electrophoretically restricted IgG by cultured rheumatoid synovium. Arthritis Rheum 1984; 27: 976-84. 
23 Carson D A, Fong S. A common idiotype on human rheumatoid factors identified by a hybridoma antibody. Mol Immunol 1983; 20: 1081-7.

24 Chen P P, Goni F, Fong S, et al. The majority of human monoclonal IgM rheumatoid factors express a 'primary structure-dependent' cross-reactive idiotype. J Immunol 1985; 134: 3281-5.

25 Ledford D K, Goni F, Pizzolato M, Franklin E C, Solomon A. Frangione B. Preferential association of xlllb light chains with monoclonal human IgM $_{k}$ autoantibodies. J Immunol 1983; 131: 1322-5.

26 Olsen N J, Jasin H E. Decreased pokeweed mitogen-induced IgM and IgM rheumatoid factor synthesis in rheumatoid arthritis patients treated with gold sodium thiomalate or penicillamine. Arthritis Rheum 1984; 27: 985-94.

27 Empire Rheumatism Council. Gold therapy in rheumatoid arthritis. Final report of a multicentre controlled trial. Ann Rheum Dis 1961; 20: 315-52.

28 Wernick R, Merryman P, Jaffe I, Ziff M. IgG and IgM rheumatoid factors in rheumatoid arthritis: quantitative response to pencillamine therapy and relationship to disease activity. Arthritis Rheum 1983; 26: 593-8.

29 Zulman J, Jaffe R, Talal N. Evidence that the malignant lymphoma of Sjögren's syndrome is a monoclonal B-cell neoplasm. N Engl J Med 1978; 299: 1215-20.

30 Strand V, Talal N. Advances in the diagnosis and concept of Sjögren's syndrome (autoimmune exocrinopathy). Bull Rheum Dis 1980; 30: 1046-52.

31 Diaz-Jouanen E, Ruiz-Arguelles G J, Vega-Ortiz J M, Villareal G, Alarcon-Segovia D. From benign polyclonal to malignant monoclonal lymphoproliferation in a patient with primary Sjögren's syndrome. Arthritis Rheum 1981; 24: 850-3.
32 Kassan S S, Thomas T L, Moutsoupoulos H M, et al. Increased risk of lymphoma in sicca syndrome. Arch Intern Med 1978; 89: 888-92.

33 Moutsopoulos H M, Steinberg A D, Fauci A S, Lane H C, Papadopoulos N M. High incidence of free monoclonal light chains in the sera of patients with Sjögren's syndrome. $J$ Immunol 1983; 130: 2663-5.

34 Moutsopoulos H M, Costello R, Drosos A A, Mavridis A K, Papadopoulos N M. Demonstration and identification of monoclonal proteins in the urine of patients with Sjögren's syndrome. Ann Rheum Dis 1985; 44: 109-12.

35 Zawadzki Z A, Benedek T G. Rheumatoid arthritis, dysproteinemic arthropathy, and paraproteinemia. Arthritis Rheum 1969; 12: 555-68.

36 Prior P, Symmons D P M, Hawkins C F, Scott D L, Brown R. Cancer morbidity in rheumatoid arthritis. Ann Rheum Dis 1984; 43: 128-31.

37 Symmons D P M, Ahern M, Bacon P A, et al. Lymphoproliferative malignancy in rheumatoid arthritis: a study of 20 cases. Ann Rheum Dis 1984; 43: 132-5.

38 Symmons D P $M$. Neoplasms of the immune system in rheumatoid arthritis. Am J Med 1985; 78 (suppl IA): 22-8.

39 Hakulinen T, Isomaki H, Knekt P. Rheumatoid arthritis and cancer studies based on linking nationwide registries in Finland. Am J Med 1985; 78 (suppl IA): 29-32.

40 Kinlen $\mathrm{L} \mathrm{J}$. Incidence of cancer in rheumatoid arthritis and other disorders after immunosuppressive treatment. Am J Med 1985; 78 (suppl IA): 44-9.

41 Vaughan $\mathrm{J} \mathrm{H}$. Immune system in rheumatoid arthritis: possible implication in neoplasms. Am J Med 1985; 78 (suppl IA): 6-11. 